\title{
Telemental health in Brazil: past, present and integration into primary care
}

\author{
Rodrigo da Silva Dias'1, Andrea de Fatima Horvath Marques¹, Paula Rejane Bezerra Diniz2, Tatiana Araújo Bertilino \\ da Silva², Luciana Cofiel ${ }^{1}$, Mirella Martins de Castro Mariani¹, Christiana Leal Salgado3, Ana Emilia Figueiredo de \\ Oliveira ${ }^{3}$, Euripedes Constantino Miguel Filho ${ }^{1}$, Chao Lung Wen ${ }^{4}$, Magdala de Araújo Novaes², Hermano Tavares ${ }^{1}$
}

' Department of Psychiatry, University of São Paulo Medical School (FMUSP), São Paulo, SP, Brazil.

2 Telehealth Center, Clinical Hospital, Federal University of Pernambuco (UFPE), Recife, PE, Brazil.

${ }^{3}$ Federal University of Maranhão (UFMA), São Luís, MA, Brazil.

${ }^{4}$ Discipline of Telemedicine, FMUSP, São Paulo, SP, Brazil.

Received: 1/26/2015 - Accepted: 3/2/2015

DOI: 10.1590/0101-60830000000046

\begin{abstract}
Background: Telemental Health Care has reported very good results and is included within mental health priorities by the World Health Organization. Objective: To provide an overview of the current situation of the integration of Brazilian telemedicine activities into primary health care. Methods: Critical review based on MEDLINE database, using the keywords "telemedicine", "primary health care" "mental health" and "telemental health", on websites of the Brazilian Ministry of Health and Brazilian Telehealth Network Program, and on personal communication. Results: The Brazilian Telehealth Network Program is well positioned and connects primary health care with academic centers. Regulations standards allow a broader scope of activities for psychologists, however, are more restrictive for physicians. In Brazil most of telemental health activities are focused on education and second opinion consulting. A huge challenge must be overcome considering the regional differences and the telehealth implementation experience. Research initiatives have been initiated both in the implementation and evaluation of the mental health assistance into primary health care. Discussion: Brazilian Telemental Health initiatives into Primary Care are aligned with other examples around the world, have a great potential for improving mental health care service delivery, and access to proper mental health care, especially if articulated in a national program and coordinated research.
\end{abstract}

Dias RS et al. / Arch Clin Psychiatry. 2015;42(2):41-4

Keywords: Community mental health, computers, education - psychiatric, social and political issues, interdisciplinary relations.

\section{Introduction}

Access to proper mental health treatment worldwide is disturbingly low, with a substantial mental health workforce shortage, particularly in low and middle-income countries ${ }^{1}$. In Brazil, the diversity of primary health structures and staff training hinders the development of standardized approaches for the identification and treatment of mental disorders ${ }^{2}$. In São Paulo, only $30.2 \%$ of severe mental disorder cases, $17.2 \%$ of moderate cases and $11.6 \%$ of mild cases received any type of general practitioner or specialized care within the previous 12 months ${ }^{3}$. In addition, a lack of familiarity with psychiatric diagnosis by primary care health professionals impairs proper identification, which is commonly delayed after several assessments ${ }^{4}$. To improve treatment and expand access to care, the World Health Organization's (WHO) Grand Challenges in Global Mental Health Initiative incorporated the integration of mental screening and services into routine primary health care and the application of information technologies (such as mobile technologies and telemedicine) for increased access to evidence-based care within its 25 mental health priorities for improved global mental health ${ }^{1}$. In alignment with these priorities, the application of telemedicine for mental health education and supervision of non-specialists has been identified as a priority for reducing barriers for seeking mental health treatment in Brazil ${ }^{5}$.

Information technologies has been applied in the medical and public health domains to promote clinical and mental health and improve the delivery of care through various mechanisms such as routine electronic data collection or the remote exchange of health information. mHealth is a term used to refer to the use of mobile devices (e.g., mobile phones, patient monitoring devices) in clinical and public health practice. Together, these mechanisms are referred as Telehealth ${ }^{6}$.

Telehealth has been associated with certain benefits including the improvement of qualified health services in disadvantaged and remote areas, training, professional communications and information processing between different levels of care, reductions in cost, time and travels ${ }^{6}$. It may be applied synchronously (e.g., real-time video- conferencing and telephone communication) or asynchronously (e.g., email, text messaging) ${ }^{6}$.

The delivery of mental health services through Telehealth is known as Telemental Health (TMH) or Telepsychiatry (TP). Promising TMH results have been reported in the diagnosis, assessment, and satisfaction of patients among various populations (e.g., adult, child, geriatric, and ethnic), disorders (e.g., depression, post-traumatic stress, substance abuse, autism), and a wide range of services (e.g., emergency, at home care $)^{7,8}$. TMH has been shown to be as efficient as in-person care and allows the establishment of proper doctor-patient relationships ${ }^{7,8}$. Additionally, the collection of data by electronic means provides specific advantages for mental health service delivery, including time savings, prevention of personal bias in the screening of disorders and reduction of stigmas $7,8 . \mathrm{TMH}$ facilitates successive evaluations and provides valuable information on treatment response, improving the quality of care ${ }^{7,8}$.

Based on the scenario presented above, this paper presents an update of Telehealth and the integration of TMH into primary care in Brazil.

\section{Methods}

A non-systematic literature review was conducted based on MEDLINE, using the terms "telemedicine", "primary health care", "mental health", and "telemental health". Further information was collected through the Brazilian Ministry of Health and Brazilian Telehealth Network Program websites and personal communication.

\section{Results}

\section{The outlook of telehealth in Brazil}

Initiated within university academic and research circles ${ }^{9}$, the practice of Telehealth in Brazil, has been bold and innovative, providing posi- 
tive results, improving the quality of care and has taken a significant role in the public health system ${ }^{10}$.

\section{Structure}

The practice of telemedicine began in early 1990's with local research projects and applications. In 2006, an initial nationwide strategy was established with the creation of the Rede Universitária de Telemedicina (University Telemedicine Network-RUTE, http://www.rnp.br), which linked academic hospitals into a national high-capacity information backbone to provide telemedicine and videoconferencing capabilities. In 2007, the Brazilian Telehealth Program was created by nine universities in partnership with the Brazilian government and integrated with the Primary Care Health System. In 2011 the program was expanded and denominated Programa Telessaúde Brasil Redes (Brazilian Telehealth Network Program - BTNP - www. saude.gov.br and www.telessaudebrasil.org.br) ${ }^{11}$. BTNP proposes to integrate primary care Family Health Teams (FHT) with designated university telehealth centers to improve the quality of primary care services, reduce health costs through professional training, reduce travel for patients and professionals, increase activities focused on disease prevention and support strategies that strengthen the integration between health centers. Until 2013, the BTNP was implemented in 14 states, with 14 telehealth centers in universities linking 5,034 telehealth sites (usually based on primary care health facilities) in 3,000 municipalities ${ }^{11}$.

\section{Standards and regulations}

The Brazilian Medicine Board defines and regulates telemedicine services and establishes technological infrastructure standards and regional boards to monitor services. Activities are restricted to medical video-consultations and inspections, second opinion consulting and education with physicians present in all environments ${ }^{12}$. The use of video conferencing for primary care is widely used in various medical specialties within the BTNP and features extensive technical, ethical and legal support from the Ministry of Health ${ }^{13}$.

\section{Education}

In 2010, the Brazilian Ministry of Health initiated the Universidade Aberta do Sistema Unificado de Saúde (Health System Open University for the Unified Health System - UNA-SUS - www.unasus. gov.br), an internet educational environment in collaboration with several educational institution, local authorities and other agencies, to support the ongoing training of health professionals and facilitates interactions between academic centers.

\section{Patient care}

The BTNP is most used by primary care health professionals to obtain asynchronous second opinions, usually performed in the regional telehealth centers and has been recommended before authorizing the removal of a patient to a secondary health ${ }^{10,11}$. These activities have been effective in reducing referrals to medical specialists ${ }^{13}$. National second opinion platforms have been created, such as the HealthNet ${ }^{14}$ for areas without local reference.

\section{Telemental health in Brazil}

The first TMH experiment in Brazil took place in 2007 with a pilot project for video-conference in São Lourenço do Sul between a mental health public facility for chronic mental disorders, the Centro de Atenção Psicossocial (CAPS), and outpatient units with participation of psychiatrists, general practioners, patients and relatives. After initial skepticism, the experience was incorporated in daily practice activity, reducing the number of hospitalizations ${ }^{15}$. In 2008, the first papers about TMH in Brazil were published, stressing the future impact of Telepsychiatry in Brazil16 and the relevance of internetbased strategies to deliver effective mental health interventions for children ${ }^{17}$, and a tele-education program for primary care teams using webconferencing ${ }^{18}$. The four most actives centers in Brazil are the Psychiatry Institute from the Federal University of Rio de Janeiro (www.ipub.ufrj.br/portal/ensino-e-pesquisa/telessaude), Rio Grande do Sul (RS) State Telehealth Program (www.ufrgs.br/telessauders), the Telehealth Center of the Federal University of Pernambuco (NUTES-UFPE - www.nutes.ufpe.br) and Amazonas State University (www.twlwssaudeam.org.br). Although there are several mHealth initiatives in Brazil, there is no one in progress for mental health ${ }^{19}$.

\section{Structure}

Local structural changes to establish and integrate TMH activities (i.e., video-conference environments) occur in many centers with mental health teams involved in the BTNP. The integration of mental health care into primary care is restricted to academic initiatives associated with the following areas and objectives:

(1) Coverage: extend assistance coverage of assistance to the most prevalent mental disorders.

(2) Recognition/Resolution: increase mental disorder recognition and resolution rates in primary care settings.

(3) Referral and Counter-Referral Services Integration: facilitate a direct channel of communication between the different services networks and improve medical record tracking.

(4) Training and Continuing Education: expand training and technical skills for the detection and treatment of the most prevalent mental disorders.

(5) Integration with eSUS-AB: the Brazilian ehealth strategy and patient electronic health record to primary care (http://dab. saude.gov.br/portaldab/esus.php).

Two projects are in progress at the Riberão Preto Medical School-USP, aiming to develop intuitive electronic health records management in the mental health care net via web and evaluate CAPS performance ${ }^{20,21}$.

The PROMENTAL (personal communication) project, a transdisciplinary participatory management structure with a Collaborative Community-Based Care approach ${ }^{22}$ model for mental health delivery (already initiated in Pernambuco and to be implemented in São Paulo), consists of four modules: Module 1: Brief home screening of psychiatric disorders applied by community health agents during regular home visits. Module 2: Primary Care waiting room mental health screening and therapeutic guidance. Module 3: Second Opinion Consulting and Collaborative Community Care Management, an online platform dedicated to case management and referrals provided through asynchronous and synchronous methods. Module 4: Web interactive educational platform updates and best practice of common psychiatric disorders and the use of technology tools.

Data collection will be performed using Dynamic Interview Database software (developed by University of São Paulo - USP www.escience.ime.usp.br/data/index.php/related-projects/didb), and the HealthNet Mobile platform (developed by NUTES/UFPE, www.nutes.ufpe.br/healthnet) using tablets, smartphones and psychometric screening properties will be evaluated in São Paulo and Pernambuco.

\section{Standards and regulations}

The Brazilian Medicine Board does not have specific TMH standards and regulations for physicians; therefore, the activity is restricted to medical video-consultations and inspections, second opinion consulting and education ${ }^{12}$. The Federal Board of Psychology (FBP) is less restrictive, allowing up to 20 clinical sessions staff selection activities, application testing, and the supervision of in-training psychologists. Psychologists are required to have regional board certification and follow the FBP technical standards for telehealth activities ${ }^{23}$. To date, nonspecific resolutions control nursing telemedicine activities. 


\section{Education}

Fontanive ${ }^{24}$ described the relevance of mental health education in the BTNP. Of the top 5 medical education needs, 4 lie within the mental health field (i.e. alcohol and drug abuse, depression and mood disorders, psychosis, and dementia). The mental health videoconference education program implemented by The Telehealth Center at the Federal University of Pernambuco has been rated as relevant by $95 \%$ of participants ${ }^{18}$. Two educational programs for child and adolescent mental health have been created and evaluated at the Institute of Developmental Psychiatry for Children and Adolescents (INPD - www.inpd.org.br) to: train family physician to detect and monitor children with mental health problems ${ }^{25}$ and training elementary schools teachers on the detection of mental health disorders in children ${ }^{26}$. In 2013, the Federal University of Maranhão (UFMA) with UNA-SUS (http://www.unasus.ufma.br), in partnership with the Institute of Psychiatry from the University of São Paulo (IPq-USP), completed the first distance education course for specialization in mental health in primary care and certified 364 primary care health professionals. The National Institute of Public Policy for Alcohol and Other Drugs (INPAD) at the Federal University of São Paulo ${ }^{26}$ and the UNASUS-UFMA has been developing web educational programs on alcohol and other drugs dependencies ${ }^{27}$. The IPq-USP in collaboration with the USP's Telemedicine Department are developing the Telepsychiatry for Primary Care (Telepsiquiatria para Atenção Primária) educational web page for primary care health professionals (www.nuvemdasaude.org.br/aia/index.php).

\section{Patient care}

In the area of patient care, NUTES-UFPE and the INPD proposed a cohort study to evaluate the effectiveness of mental telehealth and the screening of mental health disorders applied through mobile devices (http://inpd.org.br/projetos/projeto-15). The projects presented at the two former sections are deeply associated with providing mental health care support as well (www.nutes.ufpe.br/telessaudemental). At IPq-USP the first Brazilian randomized clinical trial on the effectiveness of telemental health for the outpatient treatment of depression is in progress (personal comunication).

\section{Discussion}

The BTNP program is well positioned to improve the quality of primary care services and the integration of FHTs with academic centers. However, telehealth standards and regulations for physicians' activities remain very restrictive. Brazilian Telemental health initiatives are in accordance with the new model for mental health in primary health-care settings ${ }^{22}$ and aligned with other examples around the world focused on integration of mental health care into primary care around the world 28 . A huge challenge must be overcome considering the regional differences and the telehealth implementation already experienced in Brazil's public health. Mainly, regarding resistance of technology implementation in the work environment, higher number of cases and with greater complexity to be followed, as well as confidentiality and health record usability by multidisciplinary teams ${ }^{15,29-31}$. Historically, now there is an opportunity to articulate a TMH national program and coordinated research to detect high-risk status, early stage disorder, combine pharmacological and psychosocial interventions in a stepped-care fashion with long-term follow-up based on scientific evidences looking forward to improve mental health care service delivery and access to proper mental health care in primary care.

\section{Funding/financial disclosure statement}

This study did not receive funding.

\section{Conflicts of interest}

None.

\section{References}

1. Collins PY, Patel V, Joestl SS, March D, Insel TR. Grand challenges in global mental health. Nature. 2011;475:27-30.

2. Guimarães FJ, Santos PKS, Soares NS, Cunha IPV, Farias JCLA, Campos Filho AS, et al. Fluxo de cuidado na rede pública de saúde mental. Cad Bras Saúde Ment. Submitted on: 3/5/2013.

3. Andrade LH, Wang Y-P, Andreoni S, Silveira CM, Alexandrino-Silva C, Siu ER, et al. Mental Disorders in Megacities: Findings from the São Paulo Megacity Mental Health Survey, Brazil. PLoS One. 2012;7(2):e31879.

4. Lampe L, Shadbolt N, Starcevic V, Boyce P, Brakoulias V, Hitching R, et al. Diagnostic processes in mental health: GPs and psychiatrists reading from the same book but on a different page. Australas Psychiatry. 2012;20:374-8.

5. Gregório G, Tomlinson M, Gerolin J, Kieling C, Moreira HC, Razzouk $D$, et al. Setting priorities for mental health research in Brazil. Rev Bras Psiquiatr. 2012;34(4):434-9.

6. American Telemedicine Association. Last accessed on 2014, March 4. Available from: http://www.americantelemed.org/home.

7. Hilty DM1, Ferrer DC, Parish MB, Johnston B, Callahan EJ, Yellowlees PM. The effectiveness of telemental health: a 2013 review. Telemed J E Health. 2013;19(6):444-54.

8. Shore JH. Telepsychiatry: videoconferencing in the delivery of psychiatric care. Am J Psychiatry. 2013;170:256-62.

9. Santos AF, Souza C, Alves HJ, Melo MCB, Santos SF. Structuring of the Brazilian Public Health System and the Development of Telehealth Activities in Brazil. Latin Am J Telehealth. 2009;1(1):5-38.

10. Haddad AE. Experiência Brasileira do Programa Nacional Telessaúde Brasil. In: Mathias I, Monteiro A. Gold Book [on-line]: inovação tecnológica em educação e saúde. Rio de Janeiro: Ed. UERJ; 2012. Available from: http://www.telessaude.uerj.br/resource/goldbook/pdf/2.pdf. Accessed on: March 4, 2014.

11. BRASIL. Ministério da Saúde. Programa Telessaúde Brasil. Brasília: Ministério. Available at: http://www.saude.gov.br. Accessed on: March 4, 2014.

12. Conselho Federal de Medicina. Resolução CFM 1643/2002. Available from: http://www.portalmedico.org.br/resolucoes/cfm/2002/1643_2002. htm. Accessed on: March 4, 2014.

13. BRASIL. Ministério da Saúde. Manual de telessaúde para a atenção básica/atenção primária em saúde. Brasília, Ministério da Saúde, 2012.

14. Barbosa AK, Novaes MA, Vasconcelos AML. A Web Application to Support Telemedicine Services in Brazil. AMIA Annu Symp Proc. 2003;2003:56-60.

15. Resmini F, Tavares AP, Sparenberg A, Russomano T, Bainy S, Timm R, et al. Telepsychiatry: a new tool for remodelling mental health assistance in South Brazil. The International eHealth, Telemedicine and Health ICT Forum, Luxembourg, 2008 - Proceedings - Chapter 12 Telepsychiatry: Why Not?, 395.

16. Guzman CS, Pignatiello A. The benefits of implementing telepsychiatry in the Brazilian Mental Health System. Rev Bras Psiquiatr. 2008;30(3):300-1.

17. Graeff-Martins AS, Flament MF, Fayyad J, Tyano S, Jensen P, Rohde LA. Diffusion of efficacious interventions for children and adolescents with mental health problems. J Child Psychol Psychiatry. 2008;49(3):335-52.

18. Novaes MA, Machiavelli JL, Villa-Verde FC, Campos-Filho AS, Rodrigues TRC. Tele-educação para educação continuada das equipes de saúde da família em saúde mental: a experiência de Pernambuco, Brasil. Interface, Comunicação, Saúde, Educação. 2012;16(43):545-56.

19. Iwaya LH, Gomes MA, Simplício MA, Carvalho TC, Dominicini CK, Sakuragui RR, et al. Mobile health in emerging countries: a survey of research initiatives in Brazil. Int J Med Inform. 2013;82(5):283-98.

20. Sasso AM. Desenvolvimento de um sistema para a gestão de desempenho de um Centro de Atenção Psicossocial (CAPS). Monografia (Graduação) - Faculdade de Medicina de Ribeirão Preto e Faculdade de Filosofia Ciências e Letras de Ribeirão Preto, Universidade de São Paulo, Ribeirão Preto, 2012. $118 \mathrm{p}$.

21. Yoshiura VT, Del-ben CM, Alves D. Desenvolvimento e implantação de um sistema web para o acesso e monitoramento da rede de saúde mental. Available from: http://wiki.icmc.usp.br/images/2/2f/Mat07-atencaoHospitalar-01.pdf. Accessed on: August 12, 2014.

22. Patel V, Belkin GS, Chockalingam A, Cooper J, Saxena S, Unutzer J. Grand challenges: integrating mental health services into priority health care platforms. PLoS Med. 2013;10(5):e1001448. 
23. Conselho Federal de Psicologia. Resolução CFP 011/2012. Available from: http://site.cfp.org.br/wp-content/uploads/2012/07/Resoluxo_CFP_ nx_011-12.pdf. Accessed on: March 4, 2014.

24. Fontanive PVN. Necessidades em educação permanente percebida por profissionais médicos das equipes da estratégia saúde da família dos municípios do projeto telessaúde - RS. Tese-Mestrado. Porto Alegre: Universidade Federal do Rio Grande do Sul, 2009.

25. Lowental R. Saúde mental na infância: proposta de capacitação para atenção primária. 1. ed. São Paulo: Editora Mackenzie, 2013. v. 1. 103 p.

26. Pereira CA, Wen CL, Miguel EC, Polanczyk GV. A randomized controlled trial of a web-based training program in childhood mental health for school teachers. Eur Child Adoles Psy. Submitted July, 2013.

27. Laranjeira R, Mitsuhiro SS. Addiction research centers and the nurturing of creativity. National institute on alcohol and drugs policies, Brazil. Addiction. 2012;107(4):727-32.
28. Rebello T, Marques AH, Gureie O. Pike K. Innovative strategies for closing the mental health treatment gap globally. Curr Opin Psychiatry. 2014;27(4):308-14.

29. Reitz R, Common K, Fifield P, Stiasny E. Collaboration in the presence of an electronic health record. Fam Syst Health. 2012;30(1):72-80.

30. Mourão $\mathrm{AD}$, Neves TR. Impactos da implantação do prontuário eletrônico do paciente sobre o trabalho dos profissionais de saúde da Prefeitura Municipal de Belo Horizonte. Associação Educacional Dom Bosco. Available at: http://www.aedb.br/seget/artigos07/56_SEGET.pdf. Access on: Mar 4, 2014.

31. Cofiel LPV, Ray RK, Dias RS, Roedel PM, Gutierrez MA, Brentani H. Electronic health records requirements from the psychiatry point of view: the result of a 18 month implementation experience. BMC Medical Informatics and Decision Making, 2014. 